\title{
Hypertriglyceridemic-Waist Phenotype is Strongly Associated With Cardiovascular Risk Factor Clustering In Chinese adolescents
}

\author{
Rongrong Cai \\ Ningxia Medical University \\ Jinyu Zhou \\ Ningxia Medical University \\ Lin Bai \\ Ningxia Medical University \\ Yangyang Dong \\ Ningxia Medical University \\ Wenqing Ding ( $\nabla$ dwqdz@163.com ) \\ Ningxia Medical University
}

\section{Research Article}

Keywords: hypertriglyceridemic-waist phenotype, adolescents, cardiovascular risk factor clustering

Posted Date: December 13th, 2021

DOI: https://doi.org/10.21203/rs.3.rs-1140589/v1

License: (c) (1) This work is licensed under a Creative Commons Attribution 4.0 International License. Read Full License 


\section{Abstract}

There is limited research on the relationship between the Hypertriglyceridemic-waist (HTW) phenotype and cardiovascular risk factors (CVRFs) in adolescents, and its association with cardiovascular risk factor clustering (CVRFC) is unclear. The aim of this study was to examine the association between HTW phenotype and CVRFs and CVRFC in adolescents. A total of 1478 adolescents aged 12-18 years were classified into normal triglyceride normal waist (NTNW, 66.4\%), hypertriglyceridemia (HTG, 5.5\%), enlarged waist (EW, 22.2\%) and hypertriglyceridemia-waist (HTW, 5.8\%) according to whether triglycerides $(T G) \geq 1.47 \mathrm{mmol} / \mathrm{L}$ and waist circumference $(\mathrm{WC}) \geq 90$ th percentile by gender and age. CVRFs in this study included elevated blood pressure(BP), impaired fasting glucose(IFG), high total cholesterol(TC), low high-density lipoprotein cholesterol (HDL-C), and high low-density lipoprotein cholesterol(LDL-C). After adjusting for gender and age, the HTW phenotype had a higher risk of Elevated BP, High TC, Low HDL-C and High LDL-C compared to the NTNW phenotype(the OR and 95\% Cl were 6.00 (3.79-9.52), 4.58 (2.68-7.83), 4.21 (2.44-7.26) and 6.15 (3.39-11.14), respectively). And the HTW phenotype increased the risk of CVRFC $\geq 2$ and CVRFC $\geq 3$ compared to the NTNW phenotype, the OR and 95\% Cl were 6.64 (4.08-10.80) and 11.74 (5.95-23.13), respectively. And similar results were obtained for both sexes when stratified by gender. The area under the ROC curve (AUC) for TG combining WC in the prediction of the CVRFC $\geq 2$ and CVRFC $\geq 3$ were $0.690(0.651-0.728)$ and 0.697 (0.659-0.734) in boys, and the AUC were $0.684(0.647-0.722)$ and 0.695 (0.657-0.732) for girls(all $P<0.01$ ), which were higher than TG or WC alone. These results revealed that the HTW phenotype is closely associated with cardiovascular risk factors clustering, and TG combining WC performed better than TG or WC alone in detecting cardiovascular risk factor clustering in both genders.

\section{Background}

Cardiovascular disease (CVD) is currently the leading cause of death worldwide and contributes to millions of deaths and disability-adjusted life years lost ${ }^{1,2}$. Cardiovascular risk factors (CVRFs) mainly include hypertension, hyperglycaemia and dyslipidaemia. It has been shown that CVRFs in childhood are strongly associated with CVD in adulthood ${ }^{3}$. In recent years, the prevalence of CVRFs in adolescents has been increasing globally and cardiovascular risk factor clustering(CVRFC) is becoming younger ${ }^{4}$. Therefore, early identification of CVRFs and CVRFC in adolescents is urgent.

Hypertriglyceridemic-waist(HTW) phenotypes proposed by Lemieux et al. combines the lipid indicator triglyceride (TG) with the abdominal obesity indicator waist circumference (WC), which are considered a simple proxy for visceral obesity and metabolic dysfunction ${ }^{5}$. Previous studies have shown that the HTW phenotype is strongly associated with CVRFs, and some adult studies have concluded that the HTW phenotype is a simple and useful marker that can be used to identify CVRFs ${ }^{6-9}$. However, studies on the association between the HTW phenotype and CVRFs in adolescents are limited, and the relationship between the HTW phenotype and CVRFC is unclear.

Therefore, this study investigates the relationship between different HTW phenotypes and cardiovascular risk factors and cardiovascular risk factors clustering in urban adolescents in China, so as to provide a scientific basis for the prevention and intervention of cardiovascular disease in adolescents.

\section{Material And Methods}

\section{Study participants}

Data were obtained from a cross-sectional study consisting of 1478 adolescents aged 12-18 years, selected from three junior schools and three high schools using cluster random sampling method between 2017 and 2020 in Yinchuan city, China. Schools are first selected, then stratified according to grade level, and finally classes are randomly selected within the groupings. Individuals who had physical disabilities, deformities and congenital genetic diseases were excluded. All subjects participated in the questionnaire, physical examination and laboratory analysis. All study protocols were approved by the 
Medical Ethics Review Committee of Ningxia Medical University and all informed consents were acquired from study participants and their guardians(No.2021-G053) and conducted in accordance with the Declaration of Helsinki.

\section{Physical Measurement}

Height and weight were measured using a mechanical stadiometer(Model: ZH7082) and an electronic scale(Model: RGT140), with the subject removing shoes and heavy clothing, both measured twice and averaged for inclusion in the final analysis, to an accuracy of $0.1 \mathrm{~cm}$ and $0.1 \mathrm{~kg}$ for height and weight respectively. Waist circumference $(W C)$ was measured using a nylon tape measure and the measurements were averaged twice to an accuracy of $0.1 \mathrm{~cm}$. BMI was calculated as weight divided by the squared of height $\left(\mathrm{kg} / \mathrm{m}^{2}\right)$. Blood pressure(BP) was measured by using a calibrated electronic sphygmomanometer (Model: HEM-7012, Omron, Japan) according to the standard method by the "American Hypertension Education Project Working Group"10. A suitable cuff was chosen for the measurement $(7 \mathrm{~cm}, 9 \mathrm{~cm}, 12 \mathrm{~cm}$, etc. for BP measurement in adolescents) and the subject was seated facing the measurer and BP was measured on the right upper arm with the elbow at the same level as the sphygmomanometer and the heart. Systolic blood pressure(SBP) and diastolic blood pressure (DBP) were measured three times at 1-minute intervals, and the average of the last two readings was recorded for the final analysis(a third measurement was taken if the difference between the first two blood pressure values exceeded 10 $\mathrm{mm} \mathrm{Hg}(1 \mathrm{~mm} \mathrm{Hg}=0.133 \mathrm{kPa}))$.

\section{Biochemical Analysis}

Venous blood samples were collected after at least 12 hours of overnight fasting. fasting plasma glucose(FPG), triglycerides (TG), total cholesterol (TC), high-density lipoprotein cholesterol (HDL-C) and low-density lipoprotein cholesterol (LDL-C) were measured by using an automated biochemistry analyser (Model: AU480, American). FPG, TG and TC were detected by enzymatic methods, HDL-C and LDL-C were measured by the direct method-peroxidase method.

\section{Definitions}

Cardiovascular risk factors(CVRFs) were defined as follows ${ }^{11,12}$ : Elevated WC, WC $\geq 90$ th percentile by gender and age; Elevated BP, SBP or DBP $\geq 90$ th percentile by gender and age; impaired fasting glucose(IFG), FPG $\geq 5.6 \mathrm{mmol} / \mathrm{L}$;high TG, TG $\geq 1.47 \mathrm{mmol} / \mathrm{L}$; high TC, TC $\geq 5.18 \mathrm{mmol} / \mathrm{L}$; high LDL-C, LDL-C $\geq 3.37 \mathrm{mmol} / \mathrm{L}$; low HDL-C, HDL-C $\leq 1.03 \mathrm{mmol} / \mathrm{L}$.

Cardiovascular disease risk factor clustering (CVRFC) refers to the number of five factors as follows: elevated BP, IFG, high TC, high LDL-C and low HDL-C(High TG was not included in the definition of CVRFC in this study to avoid spurious associations). CVRFC $\geq 2$ was defined as the presence of at least two cardiovascular risk factors and CVRFC $\geq 3$ was defined as the presence of at least three cardiovascular risk factors.

The study subjects were divided into four groups according to WC and TG level:(1) normal triglyceride normal waist (NWNT): $\mathrm{TG}<1.47 \mathrm{mmol} / \mathrm{L}$ and WC<90th percentile by gender and age; (2)hypertriglyceridemia (HTG): TG $\geq 1.47 \mathrm{mmol} / \mathrm{L}$ and WC $<90 \mathrm{th}$ percentile by gender and age; (3)enlarged waist (EW): $T G<1.47 \mathrm{mmol} / \mathrm{L}$ and $\mathrm{WC} \geq 90$ th percentile by gender and age;

(4)hypertriglyceridemic-waist (HTW): TG $\geq 1.47 \mathrm{mmol} / \mathrm{L}$ and $\mathrm{WC} \geq 90$ th percentile by gender and age.

\section{Statistical analysis}

SPSS 26.0 and GraphPad Prism 7.0 were used for data analysis and mapping. All data were expressed as mean \pm standard deviation(SD) for continuous variables, $P_{50}\left(P_{25}, P_{75}\right)$ for skewed variables and percentages for categorical variables. For comparisons between groups, ANOVA were used for continuous variables, Mann-Whitney U-test for skewed variables and chi-square tests for categorical variables. Binary logistic regression analysis was used to analyze the association between 
different HTW phenotype and cardiovascular risk factors and clustering. Receiver operating characteristic (ROC) curve was used to compare the effects of TG combining WC for predicting cardiovascular risk factors clustering. Two-sided $P<0.05$ was regarded as statistically significant.

\section{Results}

A total of 1478 study participants aged 12-18 years were included in the analysis. Of these, the NTNW, HTG, EW and HTW phenotypes accounted for $66.4 \%, 5.5 \%, 22.2 \%$ and $5.8 \%$ respectively. Differences in gender, height, weight, BMI, WC, WHtR, SBP, DBP, FPG, TG, TC, HDL-C and LDL-C were found among children and adolescents with different HTW phenotypes (all $P<0.01)$.

Further analysis revealed that there were differences in the basic characteristics of both boys and girls across phenotypes (all $P<0.01$ ). The boys with the HTW phenotype had higher BMI, WC, WHtR, SBP, DBP, TG and LDL-C than those with the NTNW, HTG and EW phenotypes respectively $(P<0.05)$. And BMI, WC, WHtR, SBP, DBP, TG, and TC were all higher in girls with HTW phenotype than in girls with NTNW, HTG, and EW phenotypes, respectively (all $P<0.05$ ), as shown in Table 1 and Table 2.

Table 1

Comparison of basic characteristics of boys with different HTW phenotypes

\begin{tabular}{|c|c|c|c|c|c|c|}
\hline Variables & $\begin{array}{l}\text { NTNW } \\
(\mathrm{N}=982)\end{array}$ & $\begin{array}{l}\text { HTG } \\
(\mathrm{N}=82)\end{array}$ & $\begin{array}{l}E W \\
(N=328)\end{array}$ & $\begin{array}{l}\text { HTW } \\
(\mathrm{N}=86)\end{array}$ & $\mathrm{F} / \mathrm{H}$ & $P$ value \\
\hline Age(year) & $15.0 \pm 1.5$ & $15.3 \pm 1.5$ & $14.7 \pm 1.3^{\mathrm{ab}}$ & $14.7 \pm 1.6^{\mathrm{b}}$ & 3.88 & 0.009 \\
\hline Height(cm) & $170.2 \pm 8.1$ & $171.5 \pm 7.2$ & $174.0 \pm 6.8^{\mathrm{a}}$ & $173.6 \pm 7.3^{\mathrm{a}}$ & 11.29 & $<0.001$ \\
\hline Weight(kg) & $54.9 \pm 8.0$ & $55.4 \pm 6.1$ & $78.4 \pm 11.8^{a b}$ & $81.9 \pm 10.3^{\mathrm{abc}}$ & 394.16 & $<0.001$ \\
\hline $\operatorname{BMI}\left(\mathrm{kg} / \mathrm{m}^{2}\right)$ & $18.9 \pm 2.0$ & $18.9 \pm 2.0$ & $25.9 \pm 3.1^{\mathrm{ab}}$ & $27.2 \pm 2.8^{a b c}$ & 542.36 & $<0.001$ \\
\hline $\mathrm{WC}(\mathrm{cm})$ & $68.9 \pm 4.7$ & $70.5 \pm 4.4$ & $89.2 \pm 8.9^{\mathrm{ab}}$ & $92.7 \pm 9.0^{\mathrm{abc}}$ & 661.11 & $<0.001$ \\
\hline WHtR & $0.41 \pm 0.03$ & $0.41 \pm 0.03$ & $0.51 \pm 0.05^{\mathrm{ab}}$ & $0.53 \pm 0.06^{a b c}$ & 618.03 & $<0.001$ \\
\hline $\mathrm{SBP}(\mathrm{mm} \mathrm{Hg})$ & $111.1 \pm 10.6$ & $111.9 \pm 12.7$ & $121.0 \pm 10.1^{\mathrm{ab}}$ & $124.4 \pm 10.9^{a b c}$ & 52.36 & $<0.001$ \\
\hline DBP(mm Hg) & $65.9 \pm 7.9$ & $67.3 \pm 7.7$ & $69.5 \pm 7.0^{a}$ & $74.2 \pm 8.8^{a b c}$ & 23.82 & $<0.001$ \\
\hline FPG(mmol/L) & $4.76 \pm 0.72$ & $5.29 \pm 1.21$ & $4.83 \pm 0.60^{b}$ & $4.84 \pm 0.81^{\mathrm{b}}$ & 7.59 & $<0.001$ \\
\hline $\mathrm{TG}(\mathrm{mmol} / \mathrm{L}) \star$ & $0.82(0.66,1.02)$ & $1.67(1.57,1.84)^{a}$ & $0.97(0.77,1.23)^{a b}$ & $1.96(1.61,2.37)^{\mathrm{abc}}$ & 277.30 & $<0.001$ \\
\hline $\mathrm{TC}(\mathrm{mmol} / \mathrm{L})$ & $3.86 \pm 0.88$ & $4.61 \pm 1.11^{\mathrm{a}}$ & $3.84 \pm 0.82^{b}$ & $4.79 \pm 0.95^{\mathrm{ac}}$ & 24.21 & $<0.001$ \\
\hline $\mathrm{HDL}-\mathrm{C}(\mathrm{mmol} / \mathrm{L})$ & $1.46 \pm 0.36$ & $1.59 \pm 0.49^{a}$ & $1.24 \pm 0.28^{a b}$ & $1.25 \pm 0.35^{\mathrm{ab}}$ & 23.07 & $<0.001$ \\
\hline LDL-C(mmol/L) & $2.11 \pm 0.71$ & $2.49 \pm 0.89^{a}$ & $2.25 \pm 0.73^{a}$ & $2.90 \pm 1.38^{\mathrm{abc}}$ & 18.56 & $<0.001$ \\
\hline
\end{tabular}


Table 2

Comparison of basic characteristics of girls with different HTW phenotypes

\begin{tabular}{|c|c|c|c|c|c|c|}
\hline Variables & $\begin{array}{l}\text { NTNW } \\
(\mathrm{N}=982)\end{array}$ & $\begin{array}{l}\text { HTG } \\
(\mathrm{N}=82)\end{array}$ & $\begin{array}{l}E W \\
(N=328)\end{array}$ & $\begin{array}{l}\text { HTW } \\
(\mathrm{N}=86)\end{array}$ & $\mathrm{F} / \mathrm{H}$ & $P$ value \\
\hline Age(year) & $14.3 \pm 1.6$ & $14.2 \pm 1.5$ & $14.8 \pm 1.5^{a}$ & $14.4 \pm 1.6$ & 3.25 & 0.022 \\
\hline Height(cm) & $161.1 \pm 5.7$ & $159.6 \pm 6.5$ & $164.8 \pm 6.0^{\mathrm{ab}}$ & $163.7 \pm 6.0^{a b}$ & 18.62 & $<0.001$ \\
\hline Weight(kg) & $48.1 \pm 4.9$ & $48.7 \pm 4.8$ & $64.1 \pm 8.8^{\mathrm{ab}}$ & $66.1 \pm 9.6^{\mathrm{ab}}$ & 267.15 & $<0.001$ \\
\hline $\operatorname{BMI}\left(\mathrm{kg} / \mathrm{m}^{2}\right)$ & $18.6 \pm 1.7$ & $19.1 \pm 1.9$ & $23.6 \pm 2.8^{\mathrm{ab}}$ & $24.7 \pm 3.6^{\mathrm{abc}}$ & 237.21 & $<0.001$ \\
\hline WC(cm) & $68.7 \pm 3.8$ & $69.9 \pm 3.0$ & $82.8 \pm 6.9^{a b}$ & $85.1 \pm 8.4^{\mathrm{abc}}$ & 332.46 & $<0.001$ \\
\hline WHtR & $0.43 \pm 0.03$ & $0.44 \pm 0.02^{\mathrm{a}}$ & $0.50 \pm 0.04^{\mathrm{ab}}$ & $0.52 \pm 0.05^{\mathrm{abc}}$ & 249.56 & $<0.001$ \\
\hline SBP(mm Hg) & $106.8 \pm 9.2$ & $105.0 \pm 7.8$ & $112.2 \pm 10.6^{\mathrm{ab}}$ & $117.2 \pm 11.4^{\mathrm{abc}}$ & 22.56 & $<0.001$ \\
\hline $\mathrm{DBP}(\mathrm{mm} \mathrm{Hg})$ & $68.1 \pm 7.3$ & $67.2 \pm 5.7$ & $70.4 \pm 8.3^{\mathrm{ab}}$ & $73.4 \pm 8.8^{\mathrm{abc}}$ & 8.44 & $<0.001$ \\
\hline FPG(mmol/L) & $4.73 \pm 0.59$ & $5.00 \pm 0.97^{a}$ & $4.63 \pm 0.47^{b}$ & $4.81 \pm 0.49$ & 4.63 & 0.003 \\
\hline $\mathrm{TG}(\mathrm{mmol} / \mathrm{L}) \star$ & $0.86(0.69,1.03)$ & $1.67(1.53,1.96)^{a}$ & $0.90(0.75,1.27)^{\mathrm{ab}}$ & $1.81(1.55,2.15)^{a b c}$ & 203.94 & $<0.001$ \\
\hline $\mathrm{TC}(\mathrm{mmol} / \mathrm{L})$ & $3.91 \pm 0.95$ & $4.69 \pm 1.46^{a}$ & $4.00 \pm 0.82^{b}$ & $4.37 \pm 1.12^{\mathrm{abc}}$ & 8.92 & $<0.001$ \\
\hline $\mathrm{HDL}-\mathrm{C}(\mathrm{mmol} / \mathrm{L})$ & $1.52 \pm 0.42$ & $1.71 \pm 0.73^{\mathrm{a}}$ & $1.43 \pm 0.33^{\mathrm{ab}}$ & $1.33 \pm 0.40^{\mathrm{ab}}$ & 6.90 & $<0.001$ \\
\hline LDL-C(mmol/L) & $2.03 \pm 0.68$ & $2.40 \pm 1.01^{\mathrm{a}}$ & $2.17 \pm 0.71^{a}$ & $2.36 \pm 0.97^{a}$ & 5.02 & 0.002 \\
\hline \multicolumn{7}{|c|}{$\begin{array}{l}\text { Note: *, abnormal distribution; NTNW, normal triglyceride normal waist; HTG, hypertriglyceridemia; EW, enlarged waist; } \\
\text { HTW, hypertriglyceridemia-waist; }{ }^{a} \text { compare with NTNW group, } P<0.05 \text {; }{ }^{\text {b }} \text { compare with HTG group, } P<0.05{ }^{c}{ }^{c} \text { compare } \\
\text { with EW group, } P<0.05\end{array}$} \\
\hline
\end{tabular}

Figure 1 shows that the prevalence of elevated BP, IFG, high TC, low HDL-C, high LDL-C, CVRFC $\geq 2$ and CVRFC $\geq 3$ differed by HTW phenotype in the total population and both genders (all $P<0.05$ ).

Table 3 provides the associations between different HTW phenotypes and cardiovascular risk factors. After adjusting for gender and age, the HTW phenotype had a higher risk of Elevated BP, High TC, Low HDL-C and High LDL-C compared to the NTNW phenotype, the OR and 95\% Cl were 6.00 (3.79-9.52), 4.58 (2.68-7.83), 4.21 (2.44-7.26) and 6.15 (3.39-11.14). After gender stratification, the results showed that the HTW phenotype was a risk factor of Elevated BP, High TC, Low HDL-C and High LDL-C in boys, respectively, while the HTW phenotype was a risk factor of Elevated BP and Low HDL-C in girls(all $P<0.01)$. 
Table 3

Binary Logistic regression analysis of different HTW phenotypes and cardiovascular risk factors

\begin{tabular}{|c|c|c|c|c|c|c|}
\hline \multirow[t]{2}{*}{ Variables } & \multicolumn{2}{|l|}{ Total $^{a}$} & \multicolumn{2}{|l|}{ Boys $^{b}$} & \multicolumn{2}{|l|}{ Girls ${ }^{b}$} \\
\hline & $\mathrm{OR}(95 \% \mathrm{Cl})$ & $P$ value & $\mathrm{OR}(95 \% \mathrm{Cl})$ & $P$ value & $\mathrm{OR}(95 \% \mathrm{Cl})$ & $P$ value \\
\hline \multicolumn{7}{|l|}{ Elevate BP } \\
\hline NTNW & Reference & & Reference & & Reference & \\
\hline HTG & $0.56(0.27-1.14)$ & 0.110 & $0.55(0.19-1.57)$ & 0.263 & $0.56(0.21-1.50)$ & 0.252 \\
\hline EW & $2.86(2.16-3.79)$ & $<0.001$ & $3.04(2.05-4.52)$ & $<0.001$ & $2.62(1.75-3.93)$ & $<0.001$ \\
\hline HTW & $6.00(3.79-9.52)$ & $<0.001$ & 6.19(3.36-11.38) & $<0.001$ & $5.67(2.80-11.47)$ & $<0.001$ \\
\hline \multicolumn{7}{|l|}{ IFG } \\
\hline NTNW & Reference & & Reference & & Reference & \\
\hline HTG & $3.29(1.89-5.72)$ & $<0.001$ & $3.40(1.72-6.71)$ & $<0.001$ & $2.91(1.13-7.51)$ & 0.027 \\
\hline EW & $0.78(0.49-1.25)$ & 0.310 & $1.13(0.65-1.97)$ & 0.658 & $0.36(0.15-0.86)$ & 0.022 \\
\hline HTW & $1.54(0.47-2.98)$ & 0.204 & $1.87(0.86-4.07)$ & 0.117 & $0.91(0.25-3.24)$ & 0.879 \\
\hline \multicolumn{7}{|l|}{ High TC } \\
\hline NTNW & Reference & & Reference & & Reference & \\
\hline HTG & $2.99(1.69-5.31)$ & $<0.001$ & $2.23(0.98-5.10)$ & 0.058 & $4.13(1.80-9.46)$ & 0.001 \\
\hline EW & $1.09(0.71-1.68)$ & 0.698 & $1.12(0.58-2.17)$ & 0.738 & $0.96(0.53-1.73)$ & 0.892 \\
\hline HTW & $4.58(2.68-7.83)$ & $<0.001$ & $8.01(4.08-15.73)$ & $<0.001$ & $1.90(0.75-4.82)$ & 0.179 \\
\hline \multicolumn{7}{|c|}{ Low HDL-C } \\
\hline NTNW & Reference & & Reference & & Reference & \\
\hline HTG & $1.53(0.73-3.19)$ & 0.263 & $0.79(0.24-2.64)$ & 0.704 & $2.38(0.88-6.42)$ & 0.086 \\
\hline EW & $2.33(1.58-3.44)$ & $<0.001$ & $3.87(2.47-6.08)$ & $<0.001$ & $0.78(0.35-1.74)$ & 0.548 \\
\hline HTW & $4.21(2.44-7.26)$ & $<0.001$ & $3.62(1.80-7.29)$ & $<0.001$ & $4.91(2.07-11.63)$ & $<0.001$ \\
\hline \multicolumn{7}{|c|}{ High LDL-C } \\
\hline NTNW & Reference & & Reference & & Reference & \\
\hline HTG & $3.08(1.55-6.12)$ & 0.001 & $2.36(0.86-6.48)$ & 0.096 & $3.85(1.46-10.15)$ & 0.006 \\
\hline EW & $1.49(0.89-2.48)$ & 0.130 & $2.09(1.03-4.22)$ & 0.041 & $0.94(0.45-1.96)$ & 0.875 \\
\hline HTW & 6.15(3.39-11.14) & 0.008 & $11.10(5.31-23.22)$ & $<0.001$ & $2.20(0.75-6.45)$ & 0.150 \\
\hline
\end{tabular}

Table 4 indicates that before adjusting for variables, the HTW phenotype increased the risk of CVRFC $\geq 2$ and CVRFC $\geq 3$ compared to the NTNW phenotype. This risk persisted after adjusting for gender and age, OR and 95\% Cl were 6.64 (4.08$10.80)$ and 11.74 (5.95-23.13), respectively. After stratification by gender, the results were similar to the total population. The HTW phenotype was a risk factor for CVRFC $\geq 2$ and CVRFC $\geq 3$ in both genders before and after adjustment for age(all $P<0.01)$. 
Table 4

Binary Logistic regression analysis of different HTW phenotypes and cardiovascular risk factors clustering

CVRFC $\geq 2$

CVRFC $\geq 3$

\begin{tabular}{|c|c|c|c|c|c|c|c|}
\hline \multirow[t]{2}{*}{ Variables } & Model 1 & & Model 2 & & Model 1 & & Model 2 \\
\hline & $\mathrm{OR}(95 \% \mathrm{Cl})$ & Pvalue & $\mathrm{OR}(95 \% \mathrm{Cl})$ & Pvalue & $\mathrm{OR}(95 \% \mathrm{Cl})$ & Pvalue & $\mathrm{OR}(95 \% \mathrm{Cl})$ \\
\hline
\end{tabular}

\section{Total}

\begin{tabular}{|c|c|c|c|c|c|c|c|c|}
\hline NTNW & Reference & & Reference & & Reference & & Reference & \\
\hline HTG & $\begin{array}{l}2.16(1.22- \\
3.83)\end{array}$ & 0.008 & $\begin{array}{l}2.19(1.23- \\
3.91)\end{array}$ & 0.008 & $\begin{array}{l}3.89(1.62- \\
9.36)\end{array}$ & 0.002 & $\begin{array}{l}3.80(1.57- \\
9.19)\end{array}$ & $<0.001$ \\
\hline EW & $\begin{array}{l}1.74(1.23- \\
2.47)\end{array}$ & 0.002 & $\begin{array}{l}1.82(1.27- \\
2.61)\end{array}$ & 0.001 & $\begin{array}{l}1.45(0.70- \\
3.00)\end{array}$ & 0.321 & $\begin{array}{l}1.39(0.66- \\
2.93)\end{array}$ & 0.391 \\
\hline HTW & $\begin{array}{l}5.95(3.71- \\
9.55)\end{array}$ & $<0.001$ & $\begin{array}{l}6.64(4.08- \\
10.80)\end{array}$ & $<0.001$ & $\begin{array}{l}11.04(5.68- \\
21.44)\end{array}$ & $<0.001$ & $\begin{array}{l}11.74(5.95- \\
23.13)\end{array}$ & $<0.001$ \\
\hline
\end{tabular}

Boys

\begin{tabular}{|c|c|c|c|c|c|c|c|c|}
\hline NTNW & Reference & & Reference & & Reference & & Reference & \\
\hline HTG & $\begin{array}{l}1.69(0.73- \\
3.94)\end{array}$ & 0.225 & $\begin{array}{l}1.61(0.69- \\
3.77)\end{array}$ & 0.274 & $\begin{array}{l}3.86(1.05- \\
14.22)\end{array}$ & 0.042 & $\begin{array}{l}3.59(0.97- \\
13.34)\end{array}$ & 0.056 \\
\hline EW & $\begin{array}{l}2.82(1.78- \\
4.45)\end{array}$ & $<0.001$ & $\begin{array}{l}3.08(1.94- \\
4.91)\end{array}$ & $<0.001$ & $\begin{array}{l}1.88(0.65- \\
5.41)\end{array}$ & 0.243 & $\begin{array}{l}2.17(0.74- \\
6.33)\end{array}$ & 0.177 \\
\hline HTW & $\begin{array}{l}9.97(5.35- \\
18.55)\end{array}$ & $<0.001$ & $\begin{array}{l}11.15(5.90- \\
21.06)\end{array}$ & $<0.001$ & $\begin{array}{l}18.03(7.57- \\
42.93)\end{array}$ & $<0.001$ & $\begin{array}{l}21.10(8.62- \\
51.63)\end{array}$ & $<0.001$ \\
\hline
\end{tabular}

Girls

\begin{tabular}{|c|c|c|c|c|c|c|c|c|}
\hline NTNW & Reference & & Reference & & Reference & & Reference & \\
\hline HTG & $\begin{array}{l}2.53(1.14- \\
5.61)\end{array}$ & 0.022 & $\begin{array}{l}2.79(1.23- \\
6.34)\end{array}$ & 0.014 & $\begin{array}{l}3.42(1.03- \\
11.33)\end{array}$ & 0.045 & $\begin{array}{l}3.60(1.08- \\
12.07)\end{array}$ & 0.038 \\
\hline EW & $\begin{array}{l}0.96(0.55- \\
1.67)\end{array}$ & 0.876 & $\begin{array}{l}0.83(0.47- \\
1.46)\end{array}$ & 0.513 & $\begin{array}{l}0.98(0.36- \\
2.69)\end{array}$ & 0.965 & $\begin{array}{l}0.88(0.32- \\
2.44)\end{array}$ & 0.808 \\
\hline HTW & $\begin{array}{l}2.78(1.28- \\
6.03)\end{array}$ & $<0.001$ & $\begin{array}{l}2.89(1.30- \\
6.44)\end{array}$ & 0.009 & $\begin{array}{l}5.38(1.83- \\
15.24)\end{array}$ & 0.002 & $\begin{array}{l}5.34(1.83- \\
15.54)\end{array}$ & 0.002 \\
\hline
\end{tabular}

Note: Model 1, not adjusted; Model 2, adjusted for age(add a gender adjustment to the total)

Table 5 shows the results of the ROC curve analysis. TG combining WC performed better than TG or WC alone in detecting cardiovascular risk factor clustering. In boys, the AUC were $0.690(0.651-0.728)$ and $0.697(0.659-0.734)$ in predicting CVRFC $\geq 2$ and $C V R F C \geq 3$. And the AUC were $0.684(0.647-0.722)$ and $0.695(0.657-0.732)$ for girls in predicting CVRFC $\geq 2$ and CVRFC $\geq 3$ (all $P<0.01$ ). 
Table 5

Comparison of the area under the ROC curve of WC, TG, TG combining WC and cardiovascular risk factors clustering

\begin{tabular}{|c|c|c|c|c|c|c|c|c|c|}
\hline \multirow[t]{2}{*}{ Variables } & \multicolumn{3}{|l|}{ Total $^{a}$} & \multicolumn{3}{|l|}{ Boys $^{b}$} & \multicolumn{3}{|l|}{ Girls $^{b}$} \\
\hline & AUC & $95 \% \mathrm{Cl}$ & $\begin{array}{l}P \\
\text { value }\end{array}$ & AUC & $95 \% \mathrm{Cl}$ & $\begin{array}{l}P \\
\text { value }\end{array}$ & AUC & $95 \% \mathrm{Cl}$ & $\begin{array}{l}P \\
\text { value }\end{array}$ \\
\hline \multicolumn{10}{|l|}{$C V R F C \geq 2$} \\
\hline TG & 0.677 & $\begin{array}{l}(0.640- \\
0.715)\end{array}$ & $<0.001$ & 0.674 & $\begin{array}{l}(0.636- \\
0.712)\end{array}$ & $<0.001$ & 0.673 & $\begin{array}{l}(0.635- \\
0.710)\end{array}$ & $<0.001$ \\
\hline WC & 0.662 & $\begin{array}{l}(0.623- \\
0.701)\end{array}$ & $<0.001$ & 0.655 & $\begin{array}{l}(0.616- \\
0.695)\end{array}$ & $<0.001$ & 0.651 & $\begin{array}{l}(0.613- \\
0.689)\end{array}$ & $<0.001$ \\
\hline $\begin{array}{l}\text { TG combining } \\
\text { WC }\end{array}$ & 0.696 & $\begin{array}{l}(0.659- \\
0.734)\end{array}$ & $<0.001$ & 0.690 & $\begin{array}{l}(0.651- \\
0.728)\end{array}$ & $<0.001$ & 0.684 & $\begin{array}{l}(0.647- \\
0.722)\end{array}$ & $<0.001$ \\
\hline \multicolumn{10}{|l|}{$C V R F C \geq 3$} \\
\hline TG & 0.773 & $\begin{array}{l}(0.719- \\
0.827)\end{array}$ & $<0.001$ & 0.677 & $\begin{array}{l}(0.639- \\
0.714)\end{array}$ & $<0.001$ & 0.677 & $\begin{array}{l}(0.639- \\
0.714)\end{array}$ & $<0.001$ \\
\hline WC & 0.719 & $\begin{array}{l}(0.654- \\
0.784)\end{array}$ & $<0.001$ & 0.659 & $\begin{array}{l}(0.620- \\
0.699)\end{array}$ & $<0.001$ & 0.659 & $\begin{array}{l}(0.619- \\
0.698)\end{array}$ & $<0.001$ \\
\hline $\begin{array}{l}\text { TG combining } \\
\text { WC }\end{array}$ & 0.782 & $\begin{array}{l}(0.725- \\
0.840)\end{array}$ & $<0.001$ & 0.697 & $\begin{array}{l}(0.659- \\
0.734)\end{array}$ & $<0.001$ & 0.695 & $\begin{array}{l}(0.657- \\
0.732)\end{array}$ & $<0.001$ \\
\hline
\end{tabular}

\section{Discussion}

Firstly, in this study, we found that after adjusting for gender and age, the HTW phenotype had a higher risk of Elevated BP, High TC, Low HDL-C and High LDL-C compared to the NTNW phenotype. After gender stratification, similar results were obtained for boys, however, the HTW phenotype was a risk factor for elevated BP and low HDL-C in girls. Secondly, further studies showed that the HTW phenotype increased the risk of CVRFC $\geq 2$ and CVRFC $\geq 3$ compared to the NTNW phenotype. Moreover, similar results were obtained for both sexes when stratified by gender. Finally, ROC curve analysis showed that TG combining WC performed better than TG or WC alone in detecting CVRFC $\geq 2$ and CVRFC $\geq 3$.

A one-year cohort study of children and adolescents showed that the HTW phenotype was a risk factor for longitudinal changes in SBP during follow-up ${ }^{13}$. Another study showed that the HTW phenotype was a strong predictor of incident hypertension, those with HTW phenotype were 2.3 times more likely to develop hypertension than those with NTNW phenotype after adjusting for gender and age ${ }^{14}$. The results of other study also suggest that the HTW phenotype is independently associated with the risk of cardiovascular disease, with a higher prevalence of hypertension in the HTW phenotype compared to the NTNW phenotype ${ }^{8}$. Those are consistent with the results of the present study. Esmaillzadeh et al. suggest that adolescents with the HTW phenotype are not significantly associated with the development of IFG compared to adolescents with the NTNW phenotype ${ }^{15}$. This is similar to our results. However, another study of children and adolescents identified that after adjusting for confounding variables, an increase in fasting glucose mean of $3.87 \mathrm{mg} / \mathrm{dl}$ (95\%Cl: 1.68-6.05) at one-year follow-up in those with the HTW phenotype ${ }^{13}$. Several studies in adults have also shown that the HTW phenotype is associated with IFG and even with the incident of type 2 diabetes ${ }^{6,16,17}$. This difference may be related to differences in study populations and regions, as well as the lower prevalence of IFG in adolescents in this population. Further explanation of the association between the HTW phenotype and glucose in adolescent is still needed in more studies. The study of Esmaillzadeh et al. showed that adolescents with the HTW phenotype were significantly more likely to have high TC (OR=2.9; 95\% Cl:2.0-4.2), high LDL-C (OR=1. 8; 95\% Cl: 1.3-2.7) and low HDL-C (OR=1.6; 95\%Cl:1.3-2.0) 
after controlling for potential confounding variables ${ }^{15}$. Kelishadi et al. similarly showed that HTW was associated with high TC in children and adolescents aged 10-18 years ${ }^{18}$. Adult studies have also found that individuals with the HTW phenotype have a greater chance of having low HDL-C and LDL-C compared to individuals with the NTNW phenotype ${ }^{8,19,20}$. We obtained similar results in boys, but in girls the HTW phenotype was associated with low HDL-C, but not with high TC and high HDL-C. This difference may be related to differences in gender and sex hormone levels, but more definitive underlying mechanisms need to be further investigated.

The clustering of CVRFs among adolescents is known to be associated with accelerated atherosclerosis and an increased risk of many chronic diseases, such as hypertension, hyperglycaemia and dyslipidaemia in adulthood ${ }^{21-23}$. Therefore, after confirming the association of the HTW phenotype with individual CVRFs, our study further analyzed its association with CVRFC and results presented that the HTW phenotype was related with an increased risk of CVRFC $\geq 2(\mathrm{OR}=6.64 ; 95 \% \mathrm{Cl}: 4.08$ 10.80) and $C V R F C \geq 3(\mathrm{OR}=11.74 ; 95 \% \mathrm{Cl}: 5.95-23.13)$ in adolescents. Previous studies in adolescents have shown that the HTW phenotype is a stronger risk factor for CVRFC $\geq 1(\mathrm{OR}=1.4 ; 95 \% \mathrm{Cl}: 1.1-1.7)$ and CVRFC $\geq 2(\mathrm{OR}=2.2 ; 95 \% \mathrm{Cl}: 1.6-3.0)$ compared to adolescents with the NTNW phenotype after adjusting for potential confounding variables ${ }^{15}$. This is similar to the results of our study. Another adult study showed that hypertensive adults with the HTW phenotype were significantly more likely to have all CVRFs compared to the NTNW group, and in particular for 8.35 times more likely to have CVRFC $\geq 3$ (95\% Cl: 5. 92-11.79) ${ }^{9}$. Esmaillzadeh et al. also presented a clustering of metabolic abnormalities in adolescents with the HTW phenotype and suggested this phenotype as a simple marker to identify adolescents at risk for metabolic syndrome(MetS) and other metabolic abnormalities ${ }^{15}$. The findings of Kelishadi et al. suggest that the HTW phenotypes could be used in place of all MetS component measures as a screening index for identifying children and adolescents at high risk of cardiometabolic disease in primary care settings and large epidemiological studies ${ }^{18}$.

Some adult studies have also shown that the HTW phenotype is independently associated with CVRFs and suggest that the HTW phenotype may be a simple and useful tool to screen individuals for future cardiovascular disease risk ${ }^{6,8,19}$. Liu et al. showed that the HTW phenotypes is a reliable tool for identifying MetS, with an AUC of $0.843(0.824-0.862)$ in men and 0.839 (0.813-0.865) in women ${ }^{24}$. Another study showed an AUC of 0.81 for TG*WC to predict metabolic syndrome ${ }^{25}$. In present study, TG combining WC predicted AUC of 0.690 and 0.697 for CVRFC $\geq 2$ and CVRFC $\geq 3$ in boys and 0.684 and 0.695 for CVRFC $\geq 2$ and CVRFC $\geq 3$ in girls, respectively. Lee et al. also concluded that the combination of TG and WC has been illustrated as the best indicator of overall MetS in both genders ${ }^{26}$. Other study has further confirmed that the HTW phenotype can be used as a simple and clinically useful method to identify adolescents at increased cardiometabolic risk ${ }^{27}$. A number of other studies have similarly shown that individuals with the HTW phenotype have a significantly more unfavourable cardiometabolic profile than those with the NTNW phenotype and that HTW is effective in identifying cardiometabolic risk ${ }^{7,28}$. These findings suggest that the HTW phenotype is not only strongly associated with individual cardiovascular risk factors, but also has important implications for the identification of metabolic syndromes and cardiovascular risk factor clustering.

Regarding the HTW phenotype increased risk of cardiovascular risk factors may be associated with insulin resistance and endothelial dysfunction. First, the increase in WC, a proxy for visceral adiposity, reflects to some extent the accumulation of visceral adipose tissue. In the case of central obesity, visceral adipocytes release excess fatty acids and pro-inflammatory adipocytokines such as leptin and tumour necrosis factor alpha into the portal circulation, leading to increased hepatic adiposity and insulin resistance, which further activates the renin-angiotensin-aldosterone system, increasing sympathetic activity, enhancing procoagulant activity, and inducing endothelial dysfunction, leading to hypertension and other cardiovascular diseases ${ }^{29-31}$. And a recent study found that high TG and high WC is a state of insulin resistance in adolescents $^{32}$. Besides, a Meta-analysis showed a significant correlation between the HTW phenotype and insulin resistance ${ }^{16}$. When the body has both abdominal obesity and high triglycerides, there may be a superimposed effect on insulin resistance. Insulin resistance has been identified as a major cause of increased cardiovascular risk 
factors $^{33}$. However, the underlying mechanisms regarding the relationship between HTW and cardiovascular risk factors remain unclear and require further elaboration in more studies.

Our study provides a reference for understanding the association of the HTW phenotype with individual cardiovascular risk factors and cardiovascular risk factors clustering. However, there are several limitations of the study that should be noted. Firstly, this cross-sectional study limits the causal interpretation of the observed associations. Secondly, this study did not assess some confounding factors such as lifestyle and physical activity, which may have influenced our results. Thirdly, the results cannot be generalised to other populations due to the age and ethnicity limitations of the participants.

\section{Conclusions}

In conclusion, HTW phenotype was strongly associated with individual cardiovascular risk factors and cardiovascular risk factors clustering in adolescents, TG combining WC performed better than TG or WC alone in predicting cardiovascular risk factor clustering. We suggest that the HTW phenotype can be considered as a simple and useful indicator of cardiovascular risk factors clustering in Chinese adolescents.

\section{Declarations}

\section{Acknowledgements}

The authors greatly appreciate the subjects who participated in the study.

\section{Authors' contributions}

R.C. and W.D. offered the concepts; R.C. administered the data collection with contributions from J.Z., L.B., Y.D. and W.D.; R.C. performed the data analysis and drafted the manuscript.; R.C. reviewed the manuscript with contributions from W.D.; all authors designed the study together. And they have accepted responsibility for the entire content of this submitted manuscript and approved submission.

\section{Funding}

This work was supported by Ningxia Medical University scientific research project and the National Natural Science Foundation of China (Grant number: 81660565)

\section{Competing interests}

All authors declare that they have no conflicts of interest.

\section{References}

1. GBD 2016 Causes of Death Collaborators. Global, regional, and national age-sex specific mortality for 264 causes of death, 1980-2016: a systematic analysis for the Global Burden of Disease Study 2016., 390 (10100), 1151-1210 (2017).

2. Naghavi, M. Global, regional, and national burden of suicide mortality 1990 to 2016 : systematic analysis for the Global Burden of Disease Study 2016. BMJ, 364, 194 (2019).

3. ., Koskinen Juha et al. Childhood Age and Associations Between Childhood Metabolic Syndrome and Adult Risk for Metabolic Syndrome, Type 2 Diabetes Mellitus and Carotid Intima Media Thickness: The International Childhood Cardiovascular Cohort Consortium.J Am Heart Assoc, 6(8), undefined(2017)

4. Seo Young-Gyun et al. Cardiovascular disease risk factor clustering in children and adolescents: a prospective cohort study. Arch Dis Child, 103 (10), 968-973 (2018). 
5. Lemieux, I. et al. Hypertriglyceridemic waist: A marker of the atherogenic metabolic triad (hyperinsulinemia; hyperapolipoprotein B; small, dense LDL) in men?, 102 (2), 179-84 (2000).

6. Ascaso Juan, F. et al. Millán Jesús., Mateo-Gallego Rocio., Prevalence of metabolic syndrome and cardiovascular disease in a hypertriglyceridemic population. Eur J Intern Med, 22(2), 177-81(2011)

7. Czernichow, S. et al. Hypertriglyceridemic waist and 7.5-year prospective risk of cardiovascular disease in asymptomatic middle-aged men. Int J Obes (Lond), 31 (5), 791-6 (2007).

8. Wang, A. et al. Hypertriglyceridemic waist phenotype and risk of cardiovascular diseases in China: results from the Kailuan Study. Int J Cardiol, 174 (1), 106-9 (2014).

9. Chen, S. et al. Hypertriglyceridemic waist phenotype and metabolic abnormalities in hypertensive adults: A STROBE compliant study. Med. (Baltim), 95 (49), e5613 (2016).

10. Falkner Bonita \& Daniels Stephen, R. Summary of the Fourth Report on the Diagnosis, Evaluation, and Treatment of High Blood Pressure in Children and Adolescents., 44 (4), 387-8 (2004).

11. Alberti, K. G. M. M. et al. Harmonizing the metabolic syndrome: a joint interim statement of the International Diabetes Federation Task Force on Epidemiology and Prevention; National Heart, Lung, and Blood Institute; American Heart Association; World Heart Federation; International Atherosclerosis Society; and International Association for the Study of Obesity., 120 (16), 1640-5 (2009).

12. Expert Panel on Integrated Guidelines for Cardiovascular Health and Risk Reduction in Children and Adolescents., National Heart, Lung, and Blood Institute. Expert panel on integrated guidelines for cardiovascular health and risk reduction in children and adolescents: summary report. Pediatrics, null(undefined), S213-56(2011)

13. Costa Priscila Ribas de Farias., Assis Ana Marlúcia Oliveira., Cunha Carla de Magalhães., Hypertriglyceridemic Waist Phenotype and Changes in the Fasting Glycemia and Blood Pressure in Children and Adolescents Over One-Year FollowUp Period. Arq Bras Cardiol, 109(1), 47-53(2017)

14. ., Janghorbani Mohsen., Salamat Mohammad Reza et al. Utility of the Visceral Adiposity Index and Hypertriglyceridemic Waist Phenotype for Predicting Incident Hypertension. Endocrinol Metab (Seoul), 32(2), 221-229(2017)

15. ., Esmaillzadeh Ahmad, Parvin, M. \& Fereidoun, A. Clustering of metabolic abnormalities in adolescents with the hypertriglyceridemic waist phenotype.Am J Clin Nutr, 83(1),36-46; quiz 183-4(2006)

16. Na, M. C. M. L. X. L. L. et al. Hypertriglyceridemic waist phenotype and abnormal glucose metabolism: a system review and meta-analysis., 64 (3), 469-485 (2019).

17. Ren Yongcheng et al. Hypertriglyceridemia-waist and risk of developing type 2 diabetes: The Rural Chinese Cohort Study. Sci Rep, 7 (1), 9072 (2017).

18. Kelishadi Roya et al. Association of hypertriglyceridemic-waist phenotype with liver enzymes and cardiometabolic risk factors in adolescents: the CASPIAN-III study. J Pediatr (Rio J), 92 (5), 512-20 (2016).

19. Freitas Roberta Souza., Fonseca Maria de Jesus Mendes da., Schmidt Maria Inês., Hypertriglyceridemic waist phenotype: associated factors and comparison with other cardiovascular and metabolic risk indicators in the ELSABrasil study. Cad Saude Publica, 34(4), e00067617(2018)

20. Borges Luiza Delazari., Comini Luma de Oliveira., de Oliveira Laura Camargo., Hypertriglyceridemic waist phenotype and associated factors in individuals with arterial hypertension and/or diabetes mellitus. J Nutr Sci, 10(undefined), e74(2021)

21. Raitakari Olli, T. et al. Kähönen., Cardiovascular risk factors in childhood and carotid artery intima-media thickness in adulthood: the Cardiovascular Risk in Young Finns Study. JAMA, 290(17), 2277-83(2003)

22. Sachdev, H. P. S. et al. Predicting adult metabolic syndrome from childhood body mass index: follow-up of the New Delhi birth cohort. Arch Dis Child, 94 (10), 768-74 (2009).

23. Koskinen Juhani, S. et al. Childhood risk factors and carotid atherosclerotic plaque in adulthood: The Cardiovascular Risk in Young Finns Study. Atherosclerosis, 293 (undefined), 18-25 (2020).

Page $11 / 12$ 
24. Liu Peng Ju., Lou Hui Ping., Zhu Yan Ning. Screening for Metabolic Syndrome Using an Integrated Continuous Index Consisting of Waist Circumference and Triglyceride: A Preliminary Cross-sectional Study. Diabetes Metab Syndr Obes, 13(undefined), 2899-2907(2020)

25. De Cuevillas Begoña \& Riezu-Boj Jose, A. A. I. The hypertriglyceridemic-waist phenotype as a valuable and integrative mirror of metabolic syndrome traits. Sci Rep, 11 (1), 21859 (2021).

26. Lee Bum Ju. Kim Jong Yeol. Identification of metabolic syndrome using phenotypes consisting of triglyceride levels with anthropometric indices in Korean adults. BMC Endocr Disord, 20 (1), 29 (2020).

27. Buchan, D. S. et al. Utility of the hypertriglyceridemic waist phenotype in the cardiometabolic risk assessment of youth stratified by body mass index. Pediatr Obes, 11 (4), 292-8 (2016).

28. Abbasi Fahim et al. Cardiometabolic Risk in South Asian Inhabitants of California: Hypertriglyceridemic Waist vs Hypertriglyceridemic Body Mass Index. Ethn Dis, 26 (2), 191-6 (2016).

29. Brock Cori, M. et al. Exercise, insulin resistance, and hypertension: a complex relationship. Metab Syndr Relat Disord, 3 (1), 60-5 (2005).

30. Hardy Olga, T. \& Czech, M. P. Corvera Silvia. What causes the insulin resistance underlying obesity? Curr Opin Endocrinol Diabetes Obes, 19 (2), 81-7 (2012).

31. Le Leslie Stephen, B. M. et al. J., Milliken Philip.,. Endothelial dysfunction: from molecular mechanisms to measurement, clinical implications, and therapeutic opportunities. Antioxid Redox Signal, 10(9), 1631-74(2008)

32. Barreiro-Ribeiro Francieli., Vasques Ana Carolina Junqueira., da Silva Cleliani de Cassia., Hypertriglyceridemic Waist Phenotype Indicates Insulin Resistance in Adolescents According to the Clamp Technique in the BRAMS Study. Child Obes, 12(6), 446-454(2016)

33. Adeva-Andany, M. Ã. M. et al. Martínez-Rodríguez Julia., González-Lucán Manuel., Insulin resistance is a cardiovascular risk factor in humans. Diabetes Metab Syndr, 13(2), 1449-1455(2019)

\section{Figures}

\section{Figure 1}

Prevalence of cardiovascular risk factors in the participants across different HTW phenotype groups Note: IFG, impaired fasting glucose; NTNW, normal triglyceride normal waist; HTG, hypertriglyceride -mia; EW, enlarged waist; HTW, hypertriglyceridemia-waist $₫ \mathrm{CVRFC}$, cardiovascular risk factor clus -tering 